\title{
The Effects of News Stories that Put Crime and Violence Into Context: Testing the Public Health Model of Reporting
}

\author{
RENITA COLEMAN \\ Manship School of Mass Communication \\ Louisiana State University \\ Baton Rouge, Louisiana, USA
}

\section{ESTHER THORSON}

\author{
School of Journalism \\ University of Missouri \\ Columbia, Missouri, USA
}

\begin{abstract}
The purpose of this study is to examine whether changing the way newspaper stories report crime and violence can induce shifts in readers' perceptions of the problem. Using an experiment that manipulates the framing and graphic presentation of newspaper stories on crime and violence, we seek to discover whether the public health model that calls for news stories to incorporate information on context, risk factors, and prevention strategies will help readers learn more about the context in which crime and violence occurs, endorse prevention strategies in addition to punishment, and become more attuned to societal risk factors and causes of crime and violence.
\end{abstract}

In the riots that resulted from the verdict in the Rodney King beating trial, approximately 200 of the 728 bars and liquor stores in South Central Los Angeles were destroyed. Residents had long complained that alcohol outlets were magnets for crime and violence, so they formed a coalition to fight the rebuilding of the liquor stores in their community (Wallack, Dorfman, Jernigan, \& Themba, 1993). The citizens in the coalition did their own study and found their neighborhood had more alcohol outlets than 13 states (Stevens, 1997). Another study showed that each alcohol outlet was associated with an additional 3.4 violent crimes in that area (Scribner, MacKinnon, \& Dwyer, 1995).

The South Central citizens educated the media about these studies and succeeded in shifting the focus on crime and violence in their area from conflicts between Blacks and Koreans to the overabundance of liquor stores (Stevens, 1994; Wallack et al., 1993). Once the local media reported this information, officials began taking action to reduce the number of alcohol outlets (Stevens, 1994).

The authors thank Lori Dorfman of the Berkeley Media Studies Group and Jane Stevens, Discovery Channel and the New York Times Online, for their leadership in articulating public health approaches to crime and violence reporting and their help in editing the news stories tested here.

Address correspondence to Renita Coleman, Manship School of Mass Communication, 220 Johnston Hall, Louisiana State University, Baton Rouge, LA 70803-7202, USA. E-mail: rcoleman@1su.edu 
The approach the South Central citizens took, of looking for the social causes of crime and violence, and treating crime and violence as preventable, is catching on. In the vanguard are public health officials and epidemiologists pushing for a change in how Americans think about violent crime (Stevens, 1994, 1997, 1998; Thompson, 1998). Violence should be considered in the same category as other deadly epidemics such as lung cancer and heart disease, public health officials say. Violence has definable risk factors, and, most importantly, it is not inevitable but is potentially preventable (Dorfman, Woodruff, Chavez, \& Wallack, 1997). Today, there is a rapid increase in violence research and prevention programs, but there is little chance of the success of such programs unless the way people think about violence is also changed (Dorfman et al., 1997; Stevens, 1997). That involves a change in the way media cover crime and violence, from reporting that individuals are responsible for violence to addressing underlying societal causes and giving crime a context that helps citizens understand where it comes from and what actions can reduce it.

Epidemiologists are using the same scientific approaches to fighting crime and violence as they did to reduce other public health problems-defining its risk factors and developing prevention strategies (Mercy, Rosenberg, Powell, Broone, \& Roper, 1993). Yet almost all media coverage of crime and violence centers on what individuals can do to help themselves; little if any reporting points out social changes that can help prevent violent crime (Dorfman et al., 1997; Stevens, 1997, 1998).

The purpose of this study is to examine whether changing the way newspaper stories report crime and violence can induce shifts in readers' perceptions of the problem. With two experiments that manipulate the framing and graphic presentation of newspaper stories on crime and violence, the study seeks to discover whether the public health model $^{1}$ that calls for news stories to incorporate information on context, risk factors, and prevention strategies will help readers learn more about the context in which crime and violence occurs, endorse prevention strategies in addition to punishment, and be more attuned to societal risk factors and causes of crime and violence.

\section{Literature Review}

The public health model is defined as an approach that sees the causes of death and injury as preventable rather than inevitable. By studying the interaction among the victims, the agent, and the environment, the public health approach seeks to define risk factors, then develop and evaluate methods to prevent problems that threaten public health. The goal of the model is to alter the basic conditions in society that give rise to and sustain such problems (Mercy et al., 1993). Although it may seem unusual to put crime and violence in the same category as heart disease or AIDS, public health officials point out that as the leading cause of death in this country, violence can and should be approached in the same way as any other deadly social disease (Dorfman et al., 1997). By categorizing violence with other public health problems and applying the same scientific tools used to control other epidemics, public health proponents believe they can convince Americans that violence is predictable and potentially preventable (Stevens, 1997). They see their task as no different from the one public health experts faced in the 1960s when they advised that

${ }^{1}$ Our use of the term "public health model of reporting" is borrowed from the framers of this approach (Dorfman et al.,1997; Stevens, 1994, 1997, 1998). As one reviewer noted, this may not be the most precise term for a public health audience since this broad field encompasses individual risk factors as well as more societally focused factors. We acknowledge this limitation but use the term "public health model of reporting" so as to unambiguously identify it with the definition of this reporting approach conceived by its framers. 
adding safety features to cars, wearing seat belts, and not drinking and driving would reduce automobile deaths and injuries. Until the 1960s, traffic accidents were blamed on "the nut behind the wheel" (Stevens, 1997, p. 11). Prevention strategies were limited to advising people to drive more safely. When researchers began identifying the role of societal and environmental risk factors in auto crashes, public health advocates took the findings to the media and sought to change the way these events were covered. The media began including the type of cars involved, road and weather conditions, and whether people were driving drunk or wearing seatbelts. Soon, perceptions of the causes of auto injuries and deaths changed, and more social policies were enacted to discourage drunk driving, build safer roads, and force car manufacturers to design safety features into cars. The rate of automobile deaths and injuries slowed (Stevens, 1997).

Crime and violence are not so different, epidemiologists say (Mercy et al., 1993). Some of the risk factors associated with high levels of many kinds of violence include poverty, racial segregation and discrimination, unemployment, alcohol, firearms, the portrayal of violence in the media, lack of education, child abuse, childhood exposure to violence, and the belief in male dominance (Stevens, 1997, p. 13).

Now that epidemiologists have identified these societal risk factors, this information is available for reporters to include in their stories, giving audiences a better perspective on the problem and more information about identified risk factors and consequences to individuals and society. Some newspapers, at least, are beginning to show signs of shifting toward emphasizing public health issues and including more external environmental factors in their portrayals of alcohol (Lemmens, Vaeth, \& Greenfield, 1999). Another study found that while most newspaper coverage was still more event-centered than analytic, there was a trend toward offering more context, analysis, and interpretations in the coverage of crimes and accidents (Barnhurst \& Mutz, 1997).

While not confining itself to coverage of crime or public health issues, the controversial public journalism movement, also called civic journalism, has also encouraged media reports to include a contextual framework that would help citizens understand the issues (Merritt, 1995). Although this inclusion of contextual information is only one of the many changes public journalism advocates, some researchers have found that some newspapers that have adopted the public journalism approach are indeed more likely to include more contextual information (Blazier \& Lemert, 2000).

However, most research has shown that the media have not routinely included public health information in their reports (Dorfman et al., 1997; Stevens, 1998). Most studies, which typically examine reporting on more conventional health problems such as illness and disease rather than crime and violence, show infrequent information of the contextual kind called for by the public health model. Several studies have found this is true for science stories (Friedman, Gomey, \& Egolf, 1992; Logan, 1998; Logan, Zengjun, \& Wilson, 2000; Nelkin, 1995). Lately, this seems to be especially true for the issue of domestic violence (Berns, 1999; Meyers, 1997). One content analysis of violence reporting showed that out of 1,791 television news stories in California, only one story had an explicit public health frame (Dorfman et al. 1997). When prevention was discussed at all, it was usually in the form of advice on personal safety. Larger societal factors were mentioned rarely. A study on youth violence by the Berkeley Media Studies group found that few stories included information about precursors or prevention strategies (Stevens, 1997). Numerous content analyses consistently show that crime is overreported in proportion to its occurrence (see Heath \& Gilbert, 1996, for a summary).

These media portrayals of crime and violence that rarely include risk factors or prevention strategies persist despite calls for more such reporting within the journalism industry (Astor, 1994; Bishop, 1993; Kirkhorn, 1996; Merritt, 1995; Stepp, 1998), and research 
shows that when risk factors and causal information on crime is included, readers are less fearful, especially with regard to local crimes (Chiricos, Padgett, \& Gertz, 2000; Heath, 1984). This is significant because media reports on crime and violence can have effects on readers' perceptions. Many studies have found that individuals exposed to extensive crime news are more fearful than those not exposed to large quantities of crime news (Einsiedel, Salomone, \& Schneider, 1984; Gebotys, Roberts, \& DasGupta, 1988; Jacob, 1984; Liska \& Baccaglini, 1990; Loo, 1995; Smith, 1984; Williams \& Dickinson, 1993).

Iyengar (1991) found that television news stories on crime framed a certain way led people to attribute responsibility to individuals, and that crime stories framed differently led people to attribute responsibility more to societal causes. His definition of "thematic" coverage has many commonalities with the type of reporting advocated by the public health model. Thematic coverage was associated with increased societal attributions, while episodic coverage - the kind employed by most news stories-was related to increased attributions of individualistic causal responsibility as well as punitive treatment. Regarding crime coverage specifically, Iyengar found that episodic reporting was the rule (1991).

One of the founders of the public journalism movement (Merritt, 1995) cites Iyengar's findings regarding episodic and thematic reporting in his call for journalist so begin "framing issues more broadly" (p. 74). Merritt's point is that thematic reporting that includes a thorough discussion of underlying issues helps encourage the "true deliberation" that is necessary to "revitalize public life"- the ultimate aim of the public journalism approach (Merritt, 1995, p. 74).

The idea of episodic and thematic reporting also forms the overarching framework for the concepts of base rate information and exemplars. Episodic reporting is made up primarily of exemplars, while thematic reporting includes much more base rate information. Exemplars are defined as case studies about individuals whose circumstances illustrate the phenomenon in question, involve only limited individual cases, and are chosen mainly for their entertaining qualities rather than the accuracy of their representation of the topic in the report. Base rate information, however, gives details of the number or proportion of people or things involved in a given social issue (Brosius \& Bathelt, 1994; Gibson \& Zillmann, 1994, 1998). Base rate information is necessary to give a thematic frame to an issue; exemplars are the hallmark of episodic reporting. The news media continue to rely on the more sensational and less reliable exemplars than the base rate information the public health model advocates for adding valuable context to reports on crime. Research shows that people tend to rely on exemplars when they form perceptions and judgments about the social issues presented. Despite its greater validity and generalizability, base rate information does not exert a strong effect on the audiences' perceptions or judgments. In fact, people tend to ignore base rate information when even flimsy specific evidence in the form of exemplars is present (Kahneman \& Tversky, 1973).

If public perceptions of crime are formed partly on the basis of media information (Stroman \& Seltzer, 1985), then, over time, media messages that emphasize certain information about crime and violence create a framework for thinking about solutions that favor certain kinds of social change over others (Ericson, Baranek, \& Chan, 1991; Leps, 1992; Scheingold, 1991; van Dijk, 1993). "There is evidence that people's perceptions of risk are subject to large and systematic biases. These misconceptions undoubtedly influence the way that people think about and respond to hazards in their personal lives. Such biases may misdirect the actions of public interest groups and government agencies, resulting in less than optimal control of risk" (Combs \& Slovic, 1979, pp. 837-838). Thus it is important to learn whether changing the way the media 
report on crime and violence to a public health model can actually change people's perceptions. If it is indeed the case that a public health approach to news stories can bring about positive attitude change, then the media may play an important role in altering the conditions in society that give rise to crime and violence.

\section{Journalistic Conventions}

Altering the way journalists cover crime and violence may be no easy task. The controversy over the public journalism movement of the 1990s is testimony to this. The conventions used to structure news stories have gained acceptance from journalists and their audiences (Graber, 1984). While journalists' routines are accepted as appropriate practice, they are not ideologically neutral. A common criticism of the news media is that they perpetuate the hegemonic view of individuals over the collective (Grabe, 1996; Iyengar, 1991; Shoemaker \& Reese, 1991). Some have suggested that journalists risk failure by offering a new point of view that challenges long-held ideas (Milio, 1985). That failure is compounded by a focus that shifts away from the individual and onto the broader environment (Wallack, 1990). An emphasis on collective solutions runs counter to Western society's basic liberal values as well as to journalists' conventions.

\section{Theoretical Framework}

Understanding what is involved in the task of changing the way journalists report crime and violence necessitates some knowledge of schema theory, frame analysis or framing theory, and attribution theory. Another relevant theoretical perspective is the role of the media in agenda setting.

Schema theory is the overarching framework under which framing theory and attribution theory can be understood. Schemas are the knowledge structures that organize people's memories (Harris, 1994). Schema theory basically says that people do not literally store and retrieve incoming information, including information they get from the media, but modify it in terms of their preexisting beliefs. The new content of media messages is comprehended through interactions with the knowledge people already have (Ajzen \& Fishbein, 1975; Brewer \& Nakamura, 1984; Petty \& Cacioppo, 1981; Rubin, 1986; Rumelhart, 1980; Thorndyke, 1984). People incorporate the new information within their previously formed schemas and draw inferences (Harris, 1994).

How people's schemas can be manipulated by the messages they receive is the subject of frame analysis. This theory says that people monitor their social environment for cues that signal when they should change their existing preconceptions or schema (Goffman, 1974). Events are "framed" or given a field of meaning within which they can be understood (Severin \& Tankard, 1992). This theory implies that cues learned from the media can be used also to make sense of our experiences and social situation (Baran \& Davis, 1995). Framing essentially involves selection and salience. The frames that the media use in stories help define problems and call attention to some things while obscuring others (Entman, 1993). What is left out also contributes to the power of frames. The idea of framing also implies that the frame has a common effect on a large portion of the audience (Entman, 1993). At the most general level, framing refers to subtle alterations in statement or presentation.

According to Entman (1993), frames have at least four functions: to define problems, diagnose causes, make moral judgments, and suggest remedies.

Framing can be viewed under the rubric of agenda setting, which is quintessentially described as the idea that the media do not tell people what to think, but what to think about (Cohen, 1963). This theory basically says that one of the effects of mass 
communication is to direct people's attention to certain problems or issues (McCombs \& Shaw, 1972). Agenda setting concerns a more macro level of influence than framing theory; whereas agenda setting deals with the subjects or topics of media messages, framing can be thought of as the focus or angle within those subjects.

Attribution theory relates to framing because how a message is framed can have an effect on how people attribute responsibility or place blame. Attribution theory says that people in Western cultures typically exaggerate the role of individuals' motives and intentions while downplaying the role of contextual or societal factors. Psychologists have termed this the fundamental attribution error (Jones, 1979). Research has shown that certain kinds of news frames tend to encourage this fundamental attribution error of placing responsibility with individuals, while other kinds of news frames are associated with a tendency to attribute responsibility more to societal factors than to individuals. Iyengar's (1991) studies of news frames and attribution of responsibility document this connection. He showed that news stories typically used either episodic frames or thematic frames. The episodic frames depicted concrete events that illustrated issues, while thematic frames put issues in a more general context. He found that episodic framing, which is the more common kind of news frame, leads to individual attribution s of responsibility. The more rare thematic frame was more likely to result in societal attributions. Attribution of responsibility is critical to social change; who citizens hold accountable for social problems can determine the kinds of solutions they choose. Iyengar argues that the media's "unswerving focus on specific episodes, individual perpetrators, victims, or other actors at the expense of more general, thematic information inhibits the attribution of political responsibility to societal factors" (p. 5). His studies found that "following exposure to episodic framing, Americans describe chronic problems such as poverty and crime not in terms of deep-seated social or economic conditions, but as mere idiosyncratic outcomes." However, when news coverage "presents a more general or analytic frame of reference ... the public's reasoning about causal and treatment responsibility shifts accordingly" (p. 137).

Crime was one of the specific issues of Iyengar's studies. A content analysis of the television news stories in his study found that crime was framed almost exclusively in episodic terms $-89 \%$ of all news stories. In addition, the stories tended to focus on violent crime (Iyengar, 1991). His results showed that episodic versus thematic coverage yielded only weak results for crime. While the episodic frame did increase attributions of individual responsibility, the effects showed strong interactions with the subject matter. For instance, episodic framing of White crime elicited higher levels of individual responsibility than the thematic framing, but these same effects were absent for stories dealing with Black crime and illegal drugs. He concludes, however, that "it is remarkable that relatively modest amounts of exposure to news about illegal drugs, white or black crime ... proved sufficient to induce significant shifts in viewers' attributions" (p. 45). His results also showed that systematic differences in attribution of responsibility were related to political ideology and party affiliation. Differences between Democrats and Republicans consistently exceeded differences between societal and individualistic attributors when it came to issues of crime, terrorism, and racial inequality (p. 107).

The interaction of race and crime was the focus of research by Peffley and colleagues (1996). In their experiment, White participants who endorsed negative stereotypes of African Americans viewed Black suspects in television crime stories as deserving of more punitive treatment than similarly portrayed White suspects. Even when confounding variables such as gender, age, party identification, and ideology were controlled for, individuals who held negative racial stereotypes had more punitive attitudes toward crime. 
The research presented here was conducted in two parts; in our first study, we coded respondents into three broad categories of world views. They are: fatalism, following Rotter's construct (Rotter, 1954; Rotter, Chance, \& Phares, 1972), just world, using Lerner's definition (Lerner, 1970, Lerner \& Matthews, 1967; Lerner \& Simmons, 1966), and comprehensibility (Silk, 1995). Fatalism was defined as viewing things as random, with no logical cause or reason. Those with fatalistic views of the world see social change as impossible, so any attempts to better the world are futile. The just world point of view was defined as seeing society as fair and the status quo as desirable. People with this point of view believe conformity to rules and authority is important, and punishment is appropriate. "People get what they deserve," is a typical comment. The concept of comprehensibility was adapted from Silk's (1995) discussion of how the press concerns itself with explaining eccentric beliefs and "thereby rendering them comprehensible and acceptable to readers." For this study, comprehensibility was defined as seeing the world as structured, predictable, and explicable. People with this world view want information and are confident they can make sense out of that information.

\section{Effects of Graphic Presentation on Readers}

Also of importance to this study of newspaper stories on crime and violence is the effect of presentation. Previous research has shown that reader knowledge nearly doubled over that of the control group when both text and graphics were used to report the same story and that background boxes containing text aided reader understanding (Griffin \& Stevenson, 1992). Other research has shown the superior effectiveness of sidebar stories (Ward, 1992) and pullout quotes (Wanta \& Gao, 1994; Wanta \& Remy, 1995) on recall of information. Research on pullout quotes is scant. Other than Wanta and colleagues' studies (Wanta \& Gao, 1994; Wanta \& Remy, 1995), the closest approximation of the effects of pullquotes are studies on the use of direct quotations versus paraphrasing in the text. Weaver and colleagues (1974) found no difference between readers of stories with direct quotes versus readers of stories with paraphrases on comprehension, retention, accuracy, believability, and other categories.

For this experiment, it was decided not to use charts and infographics because of the mixed results of their effectiveness in helping readers understand and remember information. Some research has found that infographic s aid comprehension and recall (Stark \& Hollander, 1990; Ward, 1992) while other research has found the opposite (Roller, 1980).

Based on the literature, we tested the following hypotheses:

H1a: Since the public health model of reporting gives readers more contextual and base-rate information, readers in the public health groups would learn more than readers of the traditional stories in the control group.

H1b: Readers of public health stories presented in graphic format would learn more than readers of public health stories presented in text format.

H2a: Because base-rate information was offered along with exemplars in the public health stories, readers would find the public health stories more interesting, relevant, believable, important, and informative than the traditional stories.

H2b: Readers of public health stories presented in graphic format would find the stories more interesting, relevant, believable, important, and informative than readers of the public health stories presented in text format. 
H3: Since the public health stories framed crime and violence as being preventable and offer suggestions for prevention, readers of the public health stories would support prevention more than readers of the traditional stories.

H4: Stories framed according to the public health model would lead readers in the public health groups to be more opposed to punishment approaches than readers in the control group.

H5: Since the public health model of reporting frames stories thematically rather than episodically, readers of the public health stories would make more attributions of responsibility to society rather than individuals.

H6: Stories framed according to the public health model would lead readers to agree more strongly that the stories illustrated the consequences of crime.

\section{Methodology}

\section{Study 1}

In an exploratory study, 89 graduate and undergraduate students attending a Midwestern university participated in a thought-listing protocol. Thought listing is a projective test of cognitive processing that is the principle means for gathering observations of the knowledge activated by people during message processing (Shapiro, 1994). So as not to interfere with reading itself, the procedure used a nondirective probe, soliciting reports immediately after reading was completed.

The participants were assigned randomly to one of two treatment conditions or a control group. There were approximately 30 participants in each group and equal numbers of female and male participants. Each group was exposed to one of three versions of newspaper stories about crime and violence. One treatment condition incorporated contextual and statistical information about the type of crime portrayed in the story according to the public health model of reporting. It was presented as text only. The second treatment condition also incorporated the public health information, but presented it in a graphic format-a boxed sidebar with a $30 \%$ gray screen. The third condition was the control group, with the story written in traditional newspaper style, containing no public health information, and presented as text only.

The four stories were "breaking news" stories on the subjects of domestic violence, youth violence, alcohol-related assault, and handgun-related homicide. The stories were written to be comparable to most newspapers' typical length for breaking news crime and violence stories, around 15- to 18-column inches. The study did not include the extremely short stories, often called "briefs," commonly found in newspaper reports of crimes, or the "police blotter" type news that consists of only a sentence or two. Neither did this study investigate longer newsfeatures typically written about broad issues for weekend pieces. We were concerned primarily with examining the medium-length stories on breaking news that might typically appear on the front page or local front of newspapers. The stimulus stories were approximately the same lengths and contained all the same information except for the public health material; in the control condition, additional, unrelated information about the perpetrator, victim, or the victim's family, and quotations or comments from family, friends, or officials was included in order to make the stories the same length. This information was designed to have minimal or no effect on readers' attributions of responsibility, the variable of interest in this study. Stories were presented as "clips"-individual articles that had been clipped out of a newspaper-rather than embedded in an entire newspaper page along with stories not of interest to the research. 
After exposure to the stories, participants were asked to complete a thought-listing exercise that asked participants to "Please write down all thoughts and feelings you had while reading this article, including thoughts and feelings that are not necessarily relevant to the article." Trained coders categorized the thoughts into areas of world view (just world, fatalism, and comprehensibility) broken into causes, consequences, prevention, and generalizations; attribution of responsibility (individual or societal); believability; and journalistic criticism. Approximately $10 \%$ of the protocols were randomly chosen for reliability analysis. Scott's Pi was calculated for the categories ${ }^{2}$ and ranged from .714 to 1.0 for all but one category, attribution of responsibility. For that category, Scott's $\mathrm{Pi}=.6$. However, only five thoughts about responsibility were recorded on the protocols selected for reliability analysis; disagreement on even one drove the numbers down to .6. The thoughts were also coded for valence (positive, negative, neutral).

The second part of the questionnaire asked participants if they liked the story, and if it was interesting, relevant to their lives, credible, important, and how fearful it made them. Answers were measured on a seven-point Likert scale. Other questions measured factual recall and media use with multiple choice answers, and attribution of responsibility measured on seven-point Likert scales.

The one-way ANOVA in SPSS was used to create analysis of variance tests.

The independent variables of interest were the public health text-only stories, the public health graphics stories, and the control condition of traditional stories in text only.

The dependent variables of interest for the thought-listing section were the number of thoughts in each coding category; for the questionnaire, the dependent variables were the responses to the Likert and multiple-choice items.

As a manipulation check to confirm subjects' perceptions of public health type information in the stimuli, we coded the number of comments made about the public health information such as contextual background and statistical information that was in the two public health conditions only. Respondents in the control condition made no comments about the public health information, while readers in the public health text condition made an average of .24 comments and readers in the public health graphic condition made an average of .27 comments. Post hoc tests in one-way ANOVA indicated highly significant differences between the two public health groups and the control group $(p=.0002)$; thus we felt confident in the strength of our manipulation.

\section{Results of Study 1}

In the thought-listing protocols, there were significant differences between the control group and the public health groups on several measures. Readers in the control group had significantly more thoughts about attribution of responsibility than did readers in the public health conditions. This held for both societal and individual attributions of responsibility. (See Table 1.) Planned post hoc tests using Scheffe's method showed that when it came to thoughts about society's role in crime and violence, participants who read the traditional news story had significantly more thoughts about society's responsibility for problems than did the readers of the public health stories in the text-only version $(F=3.5$, d.f. $=2,325, p=.03)$. While this finding may at first glance seem counter to the hypothesis, it can better be understood in the context of the valence of

${ }^{2}$ Reliability as calculated using Scott's Pi for each category was as follows: just world $=1.0$; fatalism $=1.0$; comprehensibility, broken into causes $=.88$, consequence s $=1.0$, prevention $=.8$, and generalizations $=.846$; attribution of responsibility $=.6$; believability $=.8$; journalistic criticism, broken into structural $=.714$, conventions $=.88$, clarity $=.714$, and public health information $=.83$. 
TABLE 1 ANOVAs of Attribution of Responsibility Thoughts by Condition

\begin{tabular}{lcccc}
\hline & $\begin{array}{c}\text { Control } \\
\text { group } \\
\text { mean }\end{array}$ & $\begin{array}{c}\text { Public } \\
\text { health-text } \\
\text { mean }\end{array}$ & $\begin{array}{c}\text { Public } \\
\text { health-graphic } \\
\text { mean }\end{array}$ & F value \\
\hline Societal & & & & \\
$\quad$ Total thoughts & .093 & .009 & .065 & $3.5 *$ \\
Negative thoughts & .000 & .009 & .037 & 2.71 \\
Positive thoughts & .000 & .000 & .000 & $5.74 * *$ \\
Neutral thoughts & .093 & .000 & .028 & \\
Individual & & & & $7.59 * * *$ \\
Total thoughts & .232 & .027 & .093 & $3.65 *$ \\
Negative thoughts & .13 & .009 & .065 & $5.05 * *$ \\
Positive thoughts & .000 & .000 & .000 & .029 \\
Neutral thoughts & .102 & .018 & &
\end{tabular}

those thoughts; the control group participants had almost no negative thoughts about society's responsibility, which was defined as critical or placing blame for the problem on social conditions such as lax laws, while the public health-graphic condition readers had the most negative thoughts about society's role in the problems of crime and violence (Means: Control-.00, Public Health-Graphic-.037). Although the difference in negative thoughts was not significant, it was marginally so $(F=2.7$, d.f. $=2,325, p=.068$. The control group readers also expressed significantly more neutral thoughts about society's responsibility than either the public health-text or public health-graphics readers $(F=5.74$, d.f. $=2,325, p=.004)$.

When viewed in this context, our finding is consistent with the hypothesis that public health information can have an effect on audiences' attributions of responsibility. From these data, the inclusion of public health information in crime and violence news stories appears to help shift people's attitudes so they become more critical of society's role in crime and violence. When readers of traditionally written stories think about society's role in the problems of crime and violence, they are simply expressing neutral statements such as "Someone should realize bad things can happen in a crowd" or "We owe it to his children to find out what happened." They are not as critical as readers of stories that include public health information. Readers of public health stories are more likely to lay responsibility at the feet of society. Typical responses included "Why did his company allow him to work there after being suspended so many times?" or "It's society that permits these murderers to go free." (Note: There were no positive thoughts about society's responsibility for crime and violence.)

Consistent with the finding that public health stories encourage criticism of society for crime and violence, the public health approach decreases attribution of responsibility toward individuals. Readers of the traditionally written crime stories had significantly more thoughts about individual responsibility than readers of public health text only stories or readers of public health graphics stories $(F=7.59, d . f .=2,325, \mathrm{p}=.0006)$. The valence of those thoughts also was as predicted; the control group had more negative thoughts and more neutral thoughts about individuals' responsibility. Sample responses include, "Not only was he inconsiderate of his own family when he decided to kill those 
TABLE 2 ANOVAs of World View Categories by Condition

\begin{tabular}{lcccc}
\hline & $\begin{array}{c}\text { Control } \\
\text { group } \\
\text { mean }\end{array}$ & $\begin{array}{c}\text { Public } \\
\text { health-text } \\
\text { mean }\end{array}$ & $\begin{array}{c}\text { Public } \\
\text { health-graphic } \\
\text { mean }\end{array}$ & F value \\
\hline Fatalism & .343 & .134 & .093 & $6.56^{* *}$ \\
Just World & .120 & .125 & .129 & .008 \\
Comprehensibility & .019 & .000 & .037 & 1.24 \\
$\quad$ Generalizations & .796 & .848 & 1.31 & $4.102^{*}$ \\
Prevention & .306 & .214 & .204 & .927 \\
Consequences & .352 & .232 & .167 & 2.83 \\
Causes & .583 & .598 & .379 & 1.88 \\
\hline
\end{tabular}

$* \mathrm{p}<.05 * * \mathrm{p}<.01$.

two men, but he simply doesn't see others' lives as important as he should"; "What the heck was she (attacker's girlfriend) doing during all of this"; "I thought that the two men could have defended themselves"; "I don't understand why the other guys didn't fight back"; or "Even if he is drunk, why would he hit someone he didn't know?" (Note: There were no positive thoughts about individual responsibility.)

When examining our world view categories, we found that readers of the traditional news stories were significantly more pessimistic than either public health condition using planned post hoc Scheffe tests $(F=6.56, d . f .=2,325, p=.0016)$. (See Table 2.) Pessimism, measured as fatalism, was defined as viewing things as random, with no logical cause or reason, following Rotter's construct (Rotter, 1954; Rotter et al., 1972). Those with fatalistic views of the world see social change as impossible, so any attempts to better the world are futile. Comments coded as fatalism were typically, "The world is getting more dangerous," "This just came out of the blue," and "There's nothing anyone could have done to prevent this." That readers of the traditional stories were significantly more likely to agree with the fatalistic statements than were readers of either type of public health story reinforces the criticism of status quo journalism as contributing to an apathetic citizenry.

The categories of just world and comprehensibility world views showed no significant differences between groups (just world $F=.0077, d . f .=2,325, p=.992$; comprehensibility $F=1.23$, d.f. $=2,325, p=.293$ ). People with the just world point of view (Lerner, 1970; Lerner \& Matthews, 1967; Lerner \& Simmons, 1966) typically see society as fair and the status quo as desirable. They believe conformity to rules and authority is important, and punishment is appropriate. "People get what they deserve," is a typical comment. The concept of comprehensibility was defined as seeing the world as structured, predictable, and explicable. People with this world view want information and are confident they can make sense out of that information. The comprehensibility worldview category was also coded according to a number of statements about causes, consequences, prevention, generalizations from individual events to larger things, and comments about needing more information to figure things out. The only subcategory that showed significant differences between groups was generalizations. In this category, the public health graphics condition showed significantly more generalization comments than either the control group or the public health text group. This was consistent with the public health model predictions since the generalizations our participants made all reflected an attempt to put events in context. 
Counter to our predictions about public health information, there were no significant differences between groups on number of thoughts about prevention, consequences, or causes (prevention $F=.927, d . f .=2,325, p=.397$; consequences $F=2.83$, d.f. $=2,325$, $p=.061$; causes $F=1.88, d . f .=2,325, p=.154$ ). We surmised that while people may have had thoughts about the public health information they had just read, they may not have been strong enough with this one-time manipulation to change attitudes. Attitudes toward prevention, consequences, and causes may be like attitudes toward products as a result of advertising - the effects become apparent only after long-term, multiple exposures. Our one-time manipulation may not have been strong enough to influence attitudes developed over years of exposure to media messages emphasizing individual responsibility framed episodically. We intend to study the longitudinal effects of public health model reporting in future studies.

However, we were encouraged by the lack of significant differences between groups regarding the number of comments about believability, clarity of the stories, the way they were written or reported, and the journalistic conventions such as naming victims, giving addresses, or the appearance of objectivity and bias. Even though the addition of public health information such as statistics and background information on crimes in general is out of the ordinary, it apparently did not make readers think the stories were more biased or unfair than traditionally written stories.

\section{Study 2}

Encouraged by the results of the thought-listing protocol, we next tested the public health model of reporting using a $3 \times 3$ factorial design. In this between-subjects experiment, 127 students at a large Midwestern university were randomly assigned to one of two treatment conditions or a control group. Again, there were approximately the same number of male and female participants. Individual group sizes ranged from 40 to 45 . Each group was exposed to one of three versions of a mock newspaper containing stories about crime and violence. Two public health conditions incorporated contextual and statistical information about the type of crime portrayed in the story according to the public health model of reporting. One public health condition was presented as text only. The other public health condition also incorporated the public health information but presented it in a graphic format - a boxed sidebar and a text-based chart. The third condition was the control group, with the story written in traditional newspaper style, containing no public health information, and presented as text only.

This time, three breaking news stories were presented, incorporated into mock pages of an actual newspaper in order to more closely simulate the way readers actually read news stories in the natural environment. To control for order effects, a Latin square design was used. Each of the three stories was presented on the front page, the local front, and an inside jump page for 27 different versions, with participants randomly assigned to the versions.

The stories were about youth violence, alcohol-related rape, and handgun-related homicide. In the youth violence story, a 17-year-old boy was shot in the leg when four other youths broke up an after-school basketball game with gunfire. Police arrested a suspect and speculated that the shooting was the result of an argument between youths from rival schools over girls and money. In the alcohol-related rape story, an 18-year-old woman reported being assaulted at a fraternity house party where alcohol was being served. In the homicide story, a 43-year-old university employee was shot in the chest and killed early one morning at a car wash. His wallet was missing and police suspect the motive was robbery. All three stories were based on actual events in the community of 
the study at least a year earlier. These stories were chosen for their potential interest and relevance to the study participants-young college students. In addition, two of the three were representative of typical crimes of that nature; that is, victims are more likely to know their assailants, sexual assaults are more likely to occur when the assailant and/or victim have been drinking, and so on. Only the murder story was atypical in that the victim was killed by strangers.

Again, we made the stories approximately the same length; additional, unrelated information about the perpetrator, victim, or the victim's family, and quotations or comments from family, friends, or officials was included in the control condition in order to adjust for the added material in the public health stories. As in the first study, all stories were written to eliminate any mention of race; names were changed to be ethnically ambiguous, and locations were fictitious to avoid any racial inferences.

After exposure, participants were asked to complete a questionnaire that measured knowledge of details in the stories using multiple choice answers, and how interesting, relevant, believable, important, and informative the stories were on seven-point Likert scales. Respondents were also asked, "What race would you say the people in this story were" and were given choices of Black, White, Hispanic, Asian, other, and not sure for both assailant and victim of each story. Attitudes toward prevention and punishment and attribution of responsibility for crime and violence were measured on 4-point Likert scales with no neutral point. Other questions collected data on media use, attention to crime in the media, political party identification, liberal-to-conservativ e ideology, and the usual demographics.

\section{Results of Study 2}

\section{Hypotheses $1 a$ and $1 b$}

To test knowledge, participants were asked to answer six factual questions for each story. The answers to the first two questions were given in all story conditions. The answers to the third and fourth questions were given only to readers of the public health stories and were presented in the text in both conditions. The answers to the fifth and sixth questions were also given only to readers of the public health stories, but were presented in the text in the public health text condition, and in the graphics in the public health graphic condition. We did not present this information to participants in the control group (traditional stories), because we wanted to see how well they would be able to answer these questions based on the amount of this kind of public health information that is commonly available in naturalistic conditions rather than in our experiment. Because participants in the control group who did not have the answers to questions 3 through 6 sometimes knew the correct answer, the scores for questions 3 through 6 were adjusted by subtracting the guess rate of the control group.

One-way ANOVAs showed no significant differences between the three groups on knowledge questions 1 and 2, as expected. However, there were significant differences on knowledge questions 3 and 4 for the handgun-related homicide story $(F=13.6, d . f .=2$, $124, p=.0005)$ and the youth crime story $(F=14.3, d . f .=2,124, p=.0005)$, and on knowledge questions 5 and 6 for the homicide story $(F=5.29, d . f .=2,124, p=.006)$. Planned post hoc analyses using Tukey's method revealed the differences to be as we hypothesized; there were significant differences between both the control group and the public health text group (youth crime 3 and $4, p=.0005$; homicide 3 and $4, p=.0005$, homicide 5 and $6, p=.018$ ) and between the control group and the public health graphic group (youth crime 3 and $4, p=.0005$; homicide 3 and $4, p=.0005$; homicide 5 and 6 , 
TABLE 3 ANOVA Results of Knowledge Variables by Story and Condition

\begin{tabular}{|c|c|c|c|}
\hline & F value & \multicolumn{2}{|c|}{ Significant post hoc means } \\
\hline \multicolumn{4}{|l|}{ Alcohol story } \\
\hline Knowledge $1 \& 2$ & .815 & & \\
\hline Knowledge $3 \& 4$ & 1.485 & & \\
\hline Knowledge $5 \& 6$ & .267 & & \\
\hline \multicolumn{4}{|l|}{ Youth story } \\
\hline Knowledge $1 \& 2$ & .155 & & \\
\hline \multirow[t]{2}{*}{ Knowledge $3 \& 4$} & $14.31 * * *$ & Control -.005 & PH-text $.632 * * *$ \\
\hline & & & PH-graphic $.47 * * *$ \\
\hline Knowledge $5 \& 6$ & 1.299 & & \\
\hline \multicolumn{4}{|l|}{ Homicide story } \\
\hline Knowledge $1 \& 2$ & 1.081 & & \\
\hline \multirow[t]{2}{*}{ Knowledge $3 \& 4$} & $13.603 * * *$ & Control .000 & PH-text $.614 * * *$ \\
\hline & & & PH-graphic $.756^{* * *}$ \\
\hline \multirow[t]{2}{*}{ Knowledge $5 \& 6$} & $5.287 * *$ & Control .000 & PH-text $.405^{*}$ \\
\hline & & & PH-graphic $.422 * * *$ \\
\hline
\end{tabular}

$* \mathrm{p}<.05 * * \mathrm{p}<.01 * * * \mathrm{p}<.001$.

$p=.01$ ) for all significant variables. Therefore, Hypothesis 1a was confirmed. (See Table 3.)

However, Hypothesis $1 \mathrm{~b}$ was not completely confirmed for all variables; in only two out of three stories were the mean knowledge scores of the public health graphic group higher than the mean knowledge scores of the public health text group. For the homicide story, the public health graphic group's mean knowledge score was .422 on questions 5 and 6 compared with the public health text group's mean knowledge score of .405; and on questions 3 and 4, the public health graphic group's mean score (.756) was also higher than the public health text group's mean score (.614). But for questions 3 and 4 of the youth crime story, the public health text group had a higher mean score (.632) than the public health-graphic group (.47), contrary to our hypothesis.

It appears that the public health information did increase readers' knowledge; however, this effect was not consistent across all stories.

\section{Hypotheses $2 a$ and $2 b$}

A factor analysis of all five variables for each story-interesting, believable, relevant, informative, and important-extracted a single factor for each story that we call "liking." (See Table 4a.) Analysis of variance of the three liking factors all showed significant differences between groups. (See Table 4b.) For the homicide liking factor and the alcohol liking factor, Tukey's post hoc analyses showed the significant differences were between the control group and the public health text group only (homicide liking $p=.013$, alcohol liking $p=.001$ ). For the youth liking factor, the significant differences were between both control group and public health text group $(p=.0005)$ and between control group and public health graphic group $(p=.046)$. However, in all cases, the mean liking factor scores were higher for the control group than for either public health group. Thus, Hypotheses $2 \mathrm{a}$ and $2 \mathrm{~b}$ were not supported. It seems that adding base rate 
TABLE 4A Factor Loadings by Factor by Retained Scale Items for Important, Relevant, Information, Interesting and Believable Statements

\begin{tabular}{lccc}
\hline & $\begin{array}{c}\text { Youth liking } \\
\text { factor }\end{array}$ & $\begin{array}{c}\text { Alcohol liking } \\
\text { factor }\end{array}$ & $\begin{array}{c}\text { Homicide liking } \\
\text { factor }\end{array}$ \\
\hline Important & .744 & .737 & .784 \\
Relevant & .714 & .732 & $*$ \\
Gave information & .597 & .677 & .747 \\
Interesting & .597 & .579 & .689 \\
Believable & .436 & .523 & .618 \\
\hline
\end{tabular}

*In the Homicide Liking factor, multicollinearity was detected between the variables Relevant and Important, so the Relevant variable was removed.

TABLE 4B ANOVA Results of Liking Factors by Story and Condition

\begin{tabular}{|c|c|c|c|c|}
\hline & $\mathrm{F}$ value & Post h & neans & \\
\hline \multirow[t]{2}{*}{ Alcohol liking factor } & $6.714 * *$ & Control .38 & PH-text & $-.315^{* * *}$ \\
\hline & & & PH-graphic & -.044 \\
\hline \multirow[t]{2}{*}{ Youth liking factor } & $7.189 * * *$ & Control .391 & PH-text & $-.319 * * *$ \\
\hline & & & PH-graphic & $-.049 *$ \\
\hline \multirow[t]{2}{*}{ Homicide liking factor } & $4.043^{*}$ & Control .303 & PH-text & $-.264 *$ \\
\hline & & & PH-graphic & -.023 \\
\hline
\end{tabular}

$* \mathrm{p}<.05 * * \mathrm{p}<.01 * * * \mathrm{p}<.001$.

information to the exemplars in an attempt to add context actually decreases readers' liking for the stories. In all cases, readers of the public health stories found them to be significantly less interesting and/or relevant, believable, informative, and important than did readers of traditionally written stories that relied on exemplars and did not present base rate information. Furthermore, while not significantly different, the means for the public health graphic groups were all lower on the liking factor than were the means for the public health text or control groups. This has serious implications if the public health model of reporting is to appeal to readers.

\section{Hypotheses 3 and 4}

Seventeen variables designed to measure readers' attitudes toward the effectiveness of prevention and punishment on crime and violence were factor analyzed. (See the Appendix for exact wording of questions.) Although the questions were designed to measure either preventive or punitive attitudes, factor analysis revealed a third, unanticipated factor, which we determined measured causal statements, that is, statements of risk factors and behaviors by the victims that may have led to the crime. ${ }^{3}$ Seven variables

${ }^{3}$ An anonymous reviewer noted that because the factors loaded as they did, we could not present a clear picture of whether there was a transition from a focus on individual risk factors to endorsement of environmental risk factors in the readers' perceptions. We agree; future research should examine this specifically to provide a better understanding of the underlying shift in attitudes. 
TABLE 5A Factor Loadings by Factor of Retained Scale Items of Causal, Punishment, and Prevention Statements

\begin{tabular}{lccc}
\hline & $\begin{array}{c}\text { Causal } \\
\text { factor }\end{array}$ & $\begin{array}{c}\text { Punishment } \\
\text { factor }\end{array}$ & $\begin{array}{c}\text { Prevention } \\
\text { factor }\end{array}$ \\
\hline Q5 - Worry in a bar & .609 & .029 & .057 \\
Q8 - Ban alcohol on campus & .585 & .067 & .013 \\
Q7 - Harsh on alcohol crime & .570 & .185 & -.068 \\
Q6 - Women vulnerable when drinking & .497 & .074 & .177 \\
Q9 - Warn teens about crowds & .421 & .237 & .0757 \\
Q13 - Make it difficult to get guns & .321 & .041 & -.038 \\
& .299 & .066 & -.183 \\
Q16 - Death penalty for all murders & -.021 & .585 & -.166 \\
Q12 - Try teens with guns as adults & .158 & .552 & -.033 \\
Q3 - Have repeat offender laws & -.017 & .465 & .139 \\
Q15 - All murders as bad as premeditated & -.018 & .421 & .268 \\
Q4 - Keep suspects in jail until trial & .249 & .328 & .002 \\
Q2 - Education is effective prevention & -.028 & .207 & .615 \\
Q14 - Don't go to isolated places & .031 & .246 & .575 \\
Q17 - Make it so criminals can't get guns & .259 & .325 & .387 \\
\hline
\end{tabular}

NOTE: Questions 1 and 10 were deleted because of low and complex loadings. Question 17 was transformed using a $1 / \mathrm{X}$ procedure to improve normality.

loaded purely on factor 1 - the causal factor, and five on factor 2 -the punishment factor. Factor 3-the prevention factor-was defined by two variables that loaded cleanly on it, and one that cross loaded with factor 2 . Neither of the pure variables on factor 3 were at .70 or higher, which would warrant cautious acceptance of a two-factor variable, so the cross-loaded variable was retained. (See Table 5a.) Interpretation of this variable ("Gun control laws should make sure that someone who has committed a crime cannot get access to a gun") revealed that it could indeed be construed as representing both prevention, since it aims to keep guns out of the hands of criminals, and punishment, since it is a form of punishment to take guns away from individuals when they commit crimes. The residuals of the reproduced correlation matrix were all low, indicating little difference between the original and the reproduced correlation matrix. Two variables were dropped from analysis because of low communalities and factor loading scores less than .3. (See Table 5a.)

Although all statements were written to reflect either punishment or prevention strategies, the emergence of a causal factor is interesting and in keeping with the public health model theory. The strongest factor, factor 1, at first glance appeared to be a mix of punishment and prevention statements. However, closer inspection revealed the causal orientation of all the variables loaded on this factor. For example, "Anytime you go to a bar or party where alcohol is served, you have to worry about someone getting drunk and doing something violent," "It's especially dangerous for women to drink alcohol because they are vulnerable to being raped," and "If states would make it more difficult to get guns, we would have fewer random murders," all reflect prevention strategies. However, as our factor analysis points out, more importantly they are reflecting readers' awareness of the risk factors of crime and violence and their 
TABLE 5B ANOVA Results of Causal, Punishment, and Prevention Factors by Condition

\begin{tabular}{lcclr}
\hline & F value & \multicolumn{3}{c}{ Post hoc means } \\
\hline Causal factor & 2.12 & Control .211 & PH-text & -.031 \\
& & & PH-graphic & -.158 \\
Punishment factor & .142 & Control .037 & PH-text & -.054 \\
& & & PH-graphic & .018 \\
Prevention factor & $3.315^{*}$ & \multirow{2}{*}{ Control -.257} & PH-text & -.084 \\
& & & PH-graphic & $.150^{*}$ \\
\hline
\end{tabular}

$* \mathrm{p}<.05$.

association with cause. These statements differ from those that loaded onto the prevention factor in that they are not blatant statements of what to do to prevent crime, but carry implications of risk and causation along with the idea of prevention. Similarly, the punitive statements that loaded on this factor also reflect an awareness of causation. For example, "Fraternities, sororities, and other university organizations that serve alcohol should be banned from participating in campus activities," "It's too easy for teenagers today to get guns; we should have harsher punishment for parents and other adults who allow teens access to guns," and "Anyone who violates the law while under the influence of alcohol should be treated more harshly than people who commit the same crime but are not under the influence" can be interpreted as twofold-both causal and punitive.

The statements that loaded on the punishment factor are all unambiguous, blatant statements of punishment. For example, "Any teenager who commits a crime with a gun should be tried as an adult," and "We need to change the laws so that repeat violent offenders are locked up for at least 25 years." The statements that loaded on the prevention factor are likewise unambiguous statements of prevention: "Education and community involvement in prevention programs are more effective in reducing crime and violence than prisons," and "I wouldn't go to an isolated place like a car wash anytime except during the day."

Analysis of variance of these three factors revealed significant differences on only one factor, the prevention factor $(F=3.315, d . f .=2,124, p=.04)$ with differences between the control group and the public health graphic group $(p=.05)$ in planned post hoc comparisons. As hypothesized, participants in the public health condition were more likely to support preventive measures than were participants in the control condition. (See Table 5b.) Therefore, Hypothesis 3 was confirmed; the public health stories did induce these readers to support prevention more than traditional stories. But Hypothesis 4 was rejected since there was no significant difference between the public health groups and the control group on attitudes toward punishment. Deeper reflection on how these seemingly contradictory attitudes can coexist reveals them to be not so contradictory after all. Individuals can endorse socially based prevention measures without rejecting individual responsibility and, therefore, punishment. Perhaps the endorsement of both social prevention measures in tandem with the desire to hold individuals accountable for their own actions and punish them accordingly represents a more sophisticated understanding of crime and violence than the either-or approach originally hypothesized.

There was also a significant gender difference on the prevention factor, with women supporting prevention statements more than men $(F=7.353$, d.f. $1, p=.008)$. 


\section{Hypothesis 5}

There was no support for the hypothesis that readers of public health stories would make more societal attributions of responsibility than individual attributions compared with readers of traditional stories. Our attribution of responsibility variables loaded onto two factors-one representing individual attributions, one representing societal attributions-just as we had planned, but analysis of variance revealed no significant differences. There were significant gender differences, however. Women made significantly more societal attributions of responsibility regarding prevention than did men $(\mathrm{F}=4.02$, d.f. $=2, p=.047)$.

\section{Hypothesis 6}

The hypothesis that readers of public health stories would agree more strongly than readers of traditional stories that the stories illustrated the consequences of crime was not supported; however, there was a significant difference between readers of the public health text version and readers of the public health graphics version $(F=5.362, d . f .=2$, $p=.006)$. Three statements of consequences, one for each story, measured on four-point Likert scales were combined (Cronbach's alpha $=.70$ ). A post hoc test revealed that readers of the public health graphic stories agreed significantly more with consequence statements such as, "This story shows that one consequence of alcohol abuse is increased sexual assaults," or "This story shows that one consequence of the increased availability of handguns is more youth violence" than did readers of the public health text-only version.

\section{Stereotyping Findings}

While no formal hypothesis about stereotyping was proposed, there were some interesting findings regarding participants' tendency to stereotype crime victims and assailants by race. Even though all stories were written to eliminate any mention of race, names were changed to be ethnically ambiguous, and locations were fictitious to avoid any racial inferences, we wondered if readers' preexisting schemas about race and crime would influence their reading of these stories. For each of the three stories, respondents were asked, "What race would you say the people in this story were?" and were given choices of Black, White, Hispanic, Asian, Other, and not sure for both assailant and victim. Despite overt attempts to present the stories in a race-neutral manner, and even after offering the option to choose "can't tell" rather than a specific race, $89.9 \%$ of this study's respondents imputed race on one or more of the six questions. Only $10.1 \%$ never imputed race. There were clear patterns of racial stereotyping by story subject as well. In the story about an alcohol-related rape at a fraternity, $79.5 \%$ of respondents said both assailant and victim were White. In the story about a shooting at an after-school basketball game, $52 \%$ of respondents said both assailant and victim were Black. The handgun-related murder at a car wash was the most ambiguous story in our study participants' minds; $49 \%$ of respondents said "can't tell" to one or more questions. Still, $22 \%$ said both assailant and victim were White, and $16.5 \%$ said the assailant was White and the victim Black. Analysis of variance revealed no significant differences on frequency of stereotyping by treatment condition; however, control group participants who read the traditional stories had a higher mean than either of the public health groups.

\section{Disscussion}

These two experiments on the cognitive and attitudinal impact of crime stories written to include a public health context are exploratory, but they suggest some significant 
possibilities and concerns. The first study provided demonstration that embedding public health information into stories can change readers' attributions of responsibility. Attitudes become more critical of society's role in crime and violence rather than simply focusing on the individual's role. In fact, there is less individual blame in the public health contexted stories, and there is less "fatalism" of the sort represented by the statement, "There's nothing anyone could have done to prevent this." But in Study 1, there was no evidence that the public health story readers thought differently about prevention, consequences, or causes. After the fact, we thought the manipulations may not have been strong enough, or the single encounter with such stories in the laboratories was not sufficient to create differentiated cognitions or attitudes about these aspects of crime.

Study 2 was designed to make the public health information more salient to individuals, in the graphic presentation, in fact, to pull out the information and locate it separately from the story itself. We also embedded the stories in simulated newspaper environments with the intent to make the experimental environment more ecologically valid.

Although there was some variation across stories, there was strong indication that both the public health text-alone material and the public health graphic condition led to greater acquisition of knowledge. But, surprisingly, the graphic condition did not consistently prove stronger than the text-alone condition. Thus people do pick up the public health information, but seem to do as well when it is in the story itself as when it occurs in a separate location.

Also surprising and certainly troubling for the perspective that the addition of public health information on crime is important for citizens to have available was the fact that the public health enhanced stories were evaluated more negatively by a factor that was a blend of interesting, believable, relevant, informative, and important. Without the feature of "liking" for stories, readers are obviously less likely to read, and lack of this most basic motivation is troubling. We do not know exactly how much of "news" people could be said to "like" in the sense used here, but clearly the impact of the approach advocated by public health professionals (Dorfman et al., 1997) will depend on explorations in writing these kinds of stories in a way that make readers evaluate them more positively.

Most important in Study 2, we found that simply reading three stories in which crime was embedded in a context that showed how the event fit into base rate and causal linkages had a significant effect on how much readers agreed with a prevention perspective. For example, people were more likely in the public health context conditions to agree that education and community involvement in prevention programs were more effective in reducing crime and violence than prisons. But, interestingly, there was no corresponding greater disagreement with punishment statements such as, "A murder that results from a robbery is just as bad as premeditated murder and perpetrators should get the same punishment." In current studies of news effects, punishment and prevention approaches are considered two ends of a single continuum. Here, however, the scales were independent of each other and that independence was validated by the fact that our experimental stories affected the prevention responses but not the punishment responses. Actually, this makes some intuitive sense in that one might strongly want to manipulate the social environment so as to increase prevention, but when prevention fails, one might be just as eager to punish individuals.

A final important aspect of Study 2 was the emergence of a nonpredicted scale of what we dubbed "causality." The items in this scale were originally designed to be either prevention or punishment items, but instead these items became a dimension independent 
of either of those other scales. They are linked by the "if-then" form. "If you go to where alcohol is served, you have to worry about violence." Or, "If states make it more difficult to get guns, there would be fewer random murders." While these statements may imply a prevention approach, they are in a form that people can better use as what might be called "rules for safer living." For our participants, these "if-then rules" are different from the classic notions of prevention and punishment. Apparently, however, the causality dimension was too strongly embedded in people for it to be significantly affected by the stories in the public health condition. The present results suggest that further foundational work is needed in identifying and classifying the kinds of ideas people have about public health issues.

As with any laboratory approach to studying the news, the usual criticisms of student subjects apply. An educated college student sample may well be different from the general population, especially in their ability to interpret statistical information, an important skill in this study. Future studies should include a more representative sample. Another major caveat is the fact that a brief reading of newspaper stories cannot be expected to produce the same kind or degree of impact that everyday reading amassed over long time periods may have. We would eventually hope that a real newspaper would be willing to adopt crime reporting of the type experimented with here, thus allowing research on the long-term effects.

Talking about crime episodes while also pointing out their pattern of occurrence, and what variables are associated with their occurrence, can produce enhanced knowledge in readers. Although we worked hard here to produce interesting and credible stories, adding the public health material did not enhance evaluations from readers. But even though the manipulation was a brief, one-time-only event, the result did demonstrate that attitudes toward prevention could be affected. The next steps we suggest are further experimenting with how these stories can be written better, in a more motivating way for readers, and with movement toward testing the long-term impact of changing our way of reporting crime to a way that helps citizens understand it as a public health disease.

\section{Practical Implications}

The public health model has some serious difficulties to overcome in addition to the fact that readers in this study did not find the stories very interesting. Beyond the problem of how to make base rate information more compelling, journalists, and even the framers of the public health model of reporting, have concerns about incorporating this approach into daily journalism. Time and space constraints are the most obvious limitations; the ability to even obtain necessary statistics and public health information is another. For example, in constructing the stimulus stories for these experiments, one of the researchers, a 15-year veteran of newspaper journalism, found it extremely difficult and often impossible to locate the necessary data on the local or state level. In the Midwestern community where the study was conducted, local law enforcement officials do not routinely collect such data in a format that is accessible to journalists. The data exist, but it must be laboriously compiled by sifting through individual arrest records and incident reports. Officials were able to provide some information-per diem costs to house suspects in the county jail, for example-but not others, including the breakdown of crimes by type of gun used, or even whether it was a handgun or long gun, and specific information on juvenile crime beyond the number of incidents per year; in this community, there was no way to find out how many instances of juvenile crime involved handguns, for example. The response of law enforcement officials to questions about providing data was typically that their job is to fight crime, not generate statistics. This experience was 
not unusual or limited to crime statistics. In the process of his research involving public health departments, researcher Craig Trumbo has run into similar problems. "As you point out, the greater difficulty came up when asking states for details on each of the investigations done in 1997. Only about half were able to provide these data. There is great nonuniformity across states in the method of record keeping (in about any context). Some states had this material on hand. Some had to dig for it a bit. A few could have dug for the data but didn't have the personnel resources to do so. And quite a few simply didn't keep those records" (Trumbo, personal communication, 2001). Neither do most reporters have the time to sift through reports of individual crimes and arrest records to build their own databases. Some journalists are learning to build their own databases; the field of computer-assisted reporting is encouraging this and training journalists to do so. However, most journalists who have the time for this are investigative reporters at large news organizations. In order to be most effective, the public health model of reporting would need to be incorporated into reporters' daily beats at all sizes of media outlets, not just the largest ones. It is encouraging for the public health model that research has shown that newspaper stories are getting longer (Barnhurst \& Mutz, 1997), since the inclusion of this type of information necessitates adding to the length of stories. However, as newshole shrinks in the face of economic pressures, this remains a concern. In this study, nearly half of each story in the public health conditions was devoted to contextual public health-type information. We deliberately made this manipulation strong in order to see if effects were present; however, devoting such a high percentage of the story to public health information is not very practical for real news organizations. It should also be repeated that, even with nearly half the story devoted to public health information, our study found it difficult to produce changes in readers' perceptions.

If the public health model is to be successful, proponents need to think of new and creative ways to introduce the concept to journalists. Suggestions that involve enormous commitments of money and staff by news organization s are not likely to be well received. For example, suggestions to hire and train a computer-assisted reporter, publish a weekly section that focuses on solutions to crime and violence, or have the violence-prevention reporter write a weekly column on the most prominent violence incidents (Stevens, 1998) may be too taxing to news organizations' already tight budgets. It may be more practical to introduce the public health model into other departments that are not so focused on deadlines. For example, feature departments have more time and space to delve into issues and do the reporting necessary to accumulate public health data, and so they can produce second-day or "follow-up" stories. It has even been suggested that the public health approach be aimed not at police reporters, but at reporters who cover medical and social policy issues. "Crime reporters are so focused on daily reporting-covering breaking crime," said one reporter, "Nor do they have the expertise to cover violence as a health issue." (Osborn, 1998, p. 12).

Public health professionals can help by assisting reporters to gain access to data. In light of the difficulties we had in even obtaining the necessary public health information for four stimulus stories, this seems like an area that cries out for reform. Finding ways to help state health departments and law enforcement officials organize pertinent records in a uniform manner and making it more accessible is an effort that public health professionals may want to undertake. Journalists themselves say they are hungry for the kind of information that adds context to their reports; in trade publications and other forums that discuss media performance, there is a glut of criticism regarding episodic reporting (Bishop, 1993; Goodman, 1993; Long, 2000; O’Brien, 1998; Paxton, 1998; Plate, 1995; Schiraldi, 1999). Journalists pay particular attention to criticism that comes from within their own profession, so perhaps they are not really ignoring calls for more thematic 
stories and contextual information but find it difficult if not impossible to get the information that would allow them to improve.

\section{References}

Astor, D. (1994). Covering kids: Children's advocacy group head says many newspapers are devoting too much space to stories about youth violence. Editor \& Publisher, 127(50), 9.

Azjen, I., \& Fishbein, M. (1975). Belief, attitude, intention, and behaviour: An introduction to theory and research. Reading, MA: Addison-Wesley.

Baran, S. J., \& Davis, D. K. (1995). Mass communication theory: Foundations, ferment and future. Belmont, CA: Wadsworth.

Barnhurst, K. G., \& Mutz, D. C. (1997). American journalism and the decline in event-centered reporting. Journal of Communication, 47(Autumn), 27-53.

Berns, N. (1999). "My problem and how I solved it:" Domestic violence in women's magazines. The Sociological Quarterly, 49(1), 85-108.

Bishop, E. (1993). Reporters ignore context of crime, says criminologist. St. Louis Journalism Review, 23(161), 1-3.

Blazier, T. F., \& Lemert, J. B. (2000). Public journalism and changes in content of the Seattle Times. Newspaper Research Journal, 21 (3), 69-80.

Brewer, W. F., \& Nakamura, G. V. (1984). The nature and functions of schemas. In R. S. Wyer, \& T. K. Srull (Eds.), Handbook of social cognition (p. 119-160). Hillsdale, NJ: Lawrence Erlbaum Associates.

Brosius, H., \& Bathelt, A. (1994). The utility of exemplars in persuasive communications. Communication Research, 21, 48-78.

Chiricos, T., Padgett, K., \& Gertz, M. (2000). Fear, TV news, and the reality of crime. Criminology, $38(3), 755-786$.

Cohen, B. C. (1963). The press and foreign policy. Princeton, NJ: Princeton University Press.

Combs, B., \& Slovic, P. (1979). Newspaper coverage of causes of death. Journalism Quarterly, 56, $837-843,849$.

Dorfman, L., Woodruff, K., Chavez, V., \& Wallack, L. (1997). Youth and violence on local television news in California. American Journal of Public Health, 87(8), 1311-1316.

Einsiedel, E. F., Salomone, K. L., \& Schneider, F. P. (1984). Crime: Effects of media exposure and personal experience on issue salience. Journalism Quarterly, 61(1), 131-136.

Entman, R. M. (1993). Framing: Toward clarification of a fractured paradigm. Journal of Communication, 43(4), 51-58.

Ericson, R. V., Baranek, P. M., \& Chan, J. B. L. (1991). Representing order: Crime, law and justice in the news media. Toronto: University of Toronto Press.

Friedman, S. M., Gomey, C. M., \& Egolf, B. P. (1992). Chernobyl coverage: How the US media treated the nuclear industry. Public Understanding of Science, 1, 305-323.

Gebotys, R. J., Roberts, J. V., \& DasGupta, B. (1988). News media use and public perceptions of crime seriousness. Canadian Journal of Criminology, 30(1), 3-16.

Goffman, E. (1974). Frame analysis. Philadelphia: University of Pennsylvania Press.

Gibson, R., \& Zillmann, D. (1994). Exaggerated versus representative exemplification in news reports: Perception of issues and personal consequences. Communication Research, 21(5), 603-624.

Gibson, R., \& Zillmann, D. (1998). Effects of citation in exemplifying testimony on issue perception. Journalism \& Mass Communication Quarterly, 75(1), 167-176.

Goodman, T. (1993, December 23). Crime and black images in TV news. New York Times, p. C14.

Grabe, M. E. (1996). Tabloid and traditional television news magazine crime stories: Crime lessons and reaffirmation of social class distinctions. Journalism and Mass Communication Quarterly, 73(4), 926-946.

Graber, D. (1984). Processing the news: How people tame the information tide. New York: Longman.

Griffin, J. L., \& Stevenson, R. L. (1992, Spring). Influence of text and graphics in increasing understanding of foreign news content. Newspaper Research Journal, pp. 85-99. 
Harris, R. J. (1994). A cognitive psychology of mass communication (2nd ed.). Hillsdale, NJ: Lawrence Erlbaum Associates.

Heath, L. (1984). Impact of newspaper crime reports on fear of crime: Multimethodological investigation. Journal of Personality and Social Psychology, 47(2), 263-276.

Heath, L., \& Gilbert, K. (1996). Mass media and the fear of crime. American Behavioral Scientist, $39(4), 379-386$.

Iyengar, S. (1991). Is anyone responsible? How television frames political issues. Chicago: University of Chicago Press.

Jacob, H. (1984). The frustration of policy: Responses to crime by American cities. Boston: Little, Brown.

Jones, E. E. (1979). The rocky road from acts to dispositions. American Psychologist, 34, 107-117.

Kahneman, D., \& Tversky, A. (1973). On the psychology of prediction. Psychological Review, 80, 237-251.

Kirkhorn, M. J. (1996). Violent crime, Nieman Reports, 50(3), 4-9.

Lemmens, P. H., Vaeth, P. A. C., \& Greenfield, T. K. (1999). Coverage of beverage alcohol issues in the print media in the United States, 1985-1991. American Journalof Public Health, 89(10), $1555-1560$.

Leps, M. C. (1992). Apprehending the criminal: The production of deviance in 19th century discourse. Durham, NC: Duke University Press.

Lerner, M. J. (1970). The desire for justice and reactions to victims. In J. Macaulay \& L. Berkowitz (Eds.), Altruism and helping behavior. New York: Academic Press.

Lerner, M. J., \& Matthews, G. (1967). Reactions to suffering of others under conditions of indirect responsibility. Journal of Personality and Social Psychology, 5(3), 319-325.

Lerner, M. J., \& Simmons, C. H. (1966). Observer's reaction to the "innocent victim": Compassion or rejection? Journal of Personality and Social Psychology, 4, 203-210.

Liska, A. E., \& Baccaglini, W. (1990). Feeling safe by comparison: Crime in the newspapers. Social Problems, 37(3), 360-374.

Logan, R. A. (1998). Three opportunities to work with the news media. Arthritis Care and Research, $11(1), 53-58$.

Logan, R. A., Zengjun, P., \& Wilson, N. F. (2000). Science and medical coverage in the Los Angeles Times and the Washington Post: A six-year perspective. Science Communication, $22(1), 5-26$.

Long, M. (2000, November 18). Crime news important, but in proper context. Atlanta JournalConstitution, p. A15.

Loo, D. D. (1995). Crime scares and media frames in the '90s. Paper presented at the Society for the Study of Social Problems, Washington, DC.

McCombs, M. E., \& Shaw, D. (1972). The agenda-setting function of the mass media. Public Opinion Quarterly, 36, 176-187.

Mercy, J. A., Rosenberg, M. L., Powell, K. E., Broone, C. V., \& Roper, W. L. (1993). Public health policy for preventing violence. Health Affairs, 12, 7-26.

Merritt, D. (1995). Public journalism and public life: Why telling the news is not enough. Hillsdale, NJ: Lawrence Erlbaum.

Meyers, M. (1997). News coverage of violence against women: Engendering blame. Newbury Park, CA: Sage.

Milio, N. (1985). Health education $=$ health instruction + health news: Media experiences in the United States, Finland, Australia, and England. In E. A. Rubinstein \& J. D. Brown (Eds.), The media, social science, and social policy for children (pp. 118-136). Norwood, NJ: Ablex.

Nelkin, D. (1995). Selling science: How the press covers science and technology (Rev. ed.). New York: W. H. Freeman.

O’Brien, R. (1998, July). Media gloss over news coverage of gun violence, journalists say. The Freedom Forum and Newseum News, pp. 1-2.

Osborn, B. B. (1998, January/February). New questions about crime coverage: Reporting violence as a public health issue. Extra! pp. 11-12.

Paxton, J. (1998). Context, contacts and accuracy were key in Paducah, Kentucky. Nieman Reports, $52(4), 9-10$. 
Peffley, M., Shields, T., \& Williams, B. (1996). The intersection of race and crime in television news stories: An experimental study. Political Communication, 13, 309-327.

Petty, R., \& Cacioppo, J. (1981). Attitudes and persuasion: Classic and contemporary approaches. Dubuque, IA: Brown.

Plate, T. (1995, October 31). Crime news, without context, equals bias. Los Angeles Times, p. B9.

Roller, B. V. (1980). Graph reading abilities of 13-year-olds. In P. A. Kolers, M. E. Wrolstad, \& H. Bouma (Eds.), Processing of visible Language 2 (pp. 305-314). New York, London: Plenum Press.

Rotter, J. B. (1954). Social learning and clinical psychology. Englewood Cliffs, NJ: Prentice-Hall.

Rotter, J. B., Chance, J., \& Phares, E. J. (Eds.). (1972). Applications of a social learning theory of personality. New York: Holt, Rinehart and Winston.

Rubin, A. (1986). Uses, gratifications, and media effects. In J. Bryant \& D. Zillmann (Eds.), Perspectives on media effects (pp. 1-16). Hillsdale, NJ: Lawrence Erlbaum.

Rumelhart, D. E. (1980). Schemata; Building blocks of cognition. In R. J. Spiro, B. C. Bruce \& W. F. Brewer (Eds.), Theoretical issues in reading comprehension (pp. 33-58). Hillsdale, NJ: Lawrence Erlbaum Associates.

Scheingold, S. A. (1991). The politics of crime: Criminal process and cultural obsession. Philadelphia: Temple University Press.

Schiraldi, V. (1999, November 22). Juvenile crime is decreasing-It's media coverage that's soaring. Los Angeles Times, p. 7.

Scribner, R., MacKinnon, D., \& Dwyer, J. (1995). The risk of assaultive violence and alcohol availability in Los Angeles County. American Journal of Public Health, 85(3), 335-340.

Severin, W. J., \& Tankard, J. W., Jr. (1992). Communication theories: Origins, methods, and uses in the mass media. New York: Longman.

Shapiro, M. A. (1994). Think-aloud and thought-list procedures in investigating mental processes. In A. Lang (Ed.), Measuring psychological responses to media messages (pp. 1-14). Hillsdale, NJ: Lawrence Erlbaum.

Shoemaker, P. J., \& Reese, S. D. (1991). Mediating the message: Theories of influences on mass media content. White Plains, NY: Longman.

Silk, M. (1995). Unsecular media. Urbana, Chicago: University of Illinois Press.

Smith, S. J. (1984). Crime in the news. British Journal of Criminology, 24(3), 289-295.

Stark, P. M., \& Hollander, B. A. (1990, August). Information graphics: Do they help readers understand news events? Presented to the Visual Communication Division of the Association for Education in Journalism and Mass Communication, Minneapolis, MN, (p. 7).

Stepp, C. S. (1998). The fallout from too much crime coverage. American Journalism Review, $20_{(3)}, 55$.

Stevens, J. E. (1994). Treating violence as an epidemic. Technology Review, 94(6), 22-28.

Stevens, J. E. (1997). Reporting on violence: A handbook for journalists. Berkeley, CA: Berkeley Media Studies Group.

Stevens, J. E. (1998). Integrating the public health perspective into reporting on violence. Nieman Reports, Winter, 38-40.

Stroman, C. A., \& Seltzer, R. (1985). Media use and perceptions of crime, Journalism Quarterly, $62(2), 340-345$.

Thompson, D. (1998, March 29). The science of violence: Guns, politics and the public health. Washington Post Magazine, pp. 12-16, 23-29.

Thorndyke, P. W. (1984). Applications of schema theory in cognitive research. In J. R. Anderson \& S. M. Kosslyn (Eds.), Tutorials in learning and memory (pp. 167-192). San Francisco: Freeman.

van Dijk, T. A. (1993). Elite discourse and racism. Newbury Park, CA: Sage.

Wallack, L. (1990). Mass media and health promotion: Promise, problem and challenge. In C. Atkin \& L. Wallack (Eds.), Mass communication and public health: Complexities and conflicts (pp. 41-51). Newbury Park, CA: Sage.

Wallack, L., Dorfman, L., Jernigan, D., \& Themba, M. (1993). Media advocacy and public health: Power for prevention. Newbury Park, CA: Sage. 
Wanta, W., \& Gao, D. (1994). Young readers and the newspaper: Information recall and perceived enjoyment, readability, and attractiveness. Journalism Quarterly, 71(4), 926-936.

Wanta, W., \& Remy, J. (1995). Information recall of 4 elements among young newspaper readers. Newspaper Research Journal, 16(2), 112-123.

Ward, D. B. (1992). The effectiveness of sidebar graphics. Journalism Quarterly, Summer, 318-326.

Weaver, D. H., Hopkins, W. W., Billings, W. H., \& Cole, R. R. (1974, Autumn). Quotes vs. paraphrases in writing: Does it make a difference to readers? Journalism Quarterly, pp. $400-404$.

Williams, P., \& Dickinson, J. (1993). Fear of crime: Read all about it? The relationship between newspaper crime reporting and fear of crime. Journal of Criminology, 33(1), 33-56.

\section{APPENDIX}

Questions used in the factor analysis that derived three factors: causal, punishment, prevention.

Please rate how well you agree with the following statements: (Strongly Disagree $=1$ to Strongly Agree = 4)

1. Besides being careful, most individuals can do very little to prevent crime and violence.

2. Education and community involvement in prevention programs are more effective in reducing crime and violence than prisons.

3. We need to change the laws so that repeat violent offenders are locked up for at least 25 years.

4. In order to protect the community, someone who is arrested should be kept in jail until his or her case comes to trial.

5. Anytime you do to a bar or party where alcohol is served, you have to worry about someone getting drunk and doing something violent.

6. It's especially dangerous for women to drink alcohol because they are vulnerable to being raped.

7. Anyone who violates the law while under the influence of alcohol should be treated more harshly than people who commit the same crime but are not under the influence.

8. Fraternities, sororities, and other university organizations that serve alcohol should be banned from participating in campus activities.

9. If I had teenage children, I would caution them against large crowds.

10. Metal detectors should be installed at the entrances to all schools and playgrounds.

11. It's too easy for teenagers today to get guns; we should have harsher punishment for parents and other adults who allow teens access to guns.

12. Any teenager who commits a crime with a gun should be tried as an adult.

13. If states would make it more difficult to get guns, we would have fewer random murders.

14. I wouldn't go to an isolated place like a car wash anytime except during the day.

15. A murder that results from a robbery is just as bad as premeditated murder and perpetrators should get the same punishment.

16. Someone who has a history of violent crime and is then convicted of murder should receive the death penalty, no matter what the circumstances.

17. Gun control laws should make sure that someone who has committed a crime cannot get access to a gun. 
Copyright of Journal of Health Communication is the property of Taylor \& Francis Ltd and its content may not be copied or emailed to multiple sites or posted to a listserv without the copyright holder's express written permission. However, users may print, download, or email articles for individual use. 